\title{
2 \\ What is Wrong with Agnostic Belief?
}

\author{
Yuval Avnur
}

What makes an agnostic neither a theist nor an atheist? This is sometimes taken to be a matter of belief about some relevant religious hypothesis; call it ' $h$ '. A theist believes that $h$ is true, while an atheist believes that $\mathrm{h}$ is false. On this way of carving up the territory, an agnostic is a non-believer; an agnostic lacks belief that $\mathrm{h}$ and lacks belief that not-h. Non-belief is in turn sometimes understood as a 'suspense of judgement', though that notion has proved difficult to analyse. ${ }^{1}$

There is another way to understand agnosticism. From a philosophical, or at least an epistemological perspective, we are interested in evidence and arguments for beliefs, not just beliefs themselves. Though theism is a metaphysical position, that $h$ (e.g. that there is a God), a theist thinker presumably also thinks that the evidence (or arguments, which I count as a sort of evidence) ultimately indicates that $h$ is true. And an atheist thinker presumably thinks that evidence ultimately indicates that $\mathrm{h}$ is false. Accordingly, an agnostic thinker should hold that evidence doesn't ultimately or sufficiently indicate either way about $h$. There are various ways for evidence to fail to ultimately indicate something, and below I will focus on a particular one. But even prior to that disambiguation, the distinction between

${ }^{1}$ See Monton (1998) and Friedman (2013) for critical discussion of some attempts to formalize an agnostic attitude. I briefly discuss Friedman's positive proposal at the end of this chapter. 
agnosticism and the first two positions with respect to evidence about $\mathrm{h}$ should be clear. So far I have left out a sort of fideism, or the attitude of believing that $\mathrm{h}$ while also believing that the evidence fails to ultimately indicate whether $h$ is true. My main question concerns this sort of position.

A couple of preliminary remarks about agnosticism as a position about evidence will be helpful, since agnosticism is so often assumed to be simply a matter of withholding belief. First, construing agnosticism as having this epistemological component is certainly consistent with the way in which the term was originally introduced: T.H. Huxley ${ }^{2}$ introduced the term in the nineteenth century by describing agnostics as ones who 'like [himself], confess themselves to be hopelessly ignorant concerning a variety of matters, about which metaphysicians and theologians, both orthodox and heterodox, dogmatise with the utmost confidence'. Regarding oneself as 'hopelessly ignorant' with respect to $\mathrm{h}$ involves, at least, thinking that the evidence does not (perhaps could not, since the situation is 'hopeless') settle whether $h$.

Second, lack of belief about $\mathrm{h}$ can be due to things like an abundance of caution, stubbornness, failure to even consider evidence, or one's regarding $\mathrm{h}$ as so fantastic, or so desirable, that one hesitates to trust what seems to one to be even a fairly solid case in favour of $h$. Surely, these ways of lacking belief about $h$ are not the only ways to be agnostic. There is also a more principled, philosophical sort of agnosticism. Taking a philosophically agnostic position is not merely a matter of lacking belief for any reason; it involves lacking belief about $\mathrm{h}$ because, roughly, one thinks that it is unknowable whether $\mathrm{h}^{3}{ }^{3}$ When this epistemological, sceptical position is fleshed out in more detail (in section I), its worthiness of the title 'agnosticism' should become clearer.

I have specified two sorts of agnosticism: non-belief (or suspense of judgement) about $h$, and belief about the insufficiency of our evidence about h. I do not aim to adjudicate which of the two (if either) should count as the most correct way of understanding agnosticism. Instead,

2 Huxley (1884).

3 For a different approach, see Schellenberg (2009) and (2013), pp. 100-106, where a notion of 'imaginative faith' is developed in the place of what I am calling 'agnosticism'. 
my aim is to consider a key question about the relation between the two. Does the position that the evidence supports neither $h$ nor not-h commit one to non-belief about h? It may well seem perverse to go to the trouble to develop a negative view of a belief's epistemic credentials, and then to hold the belief anyway-and this seems equally perverse whether we have in mind belief in theism or belief in atheism. But what, exactly, is wrong with believing something that you are agnostic about in the second, epistemological sense? What is wrong with believing $\mathrm{h}$ (or not-h) while also believing that there can be no evidence about $h$ ? That will be my main question, and I will call belief in a proposition that one is also epistemologically agnostic about 'agnostic belief'.

I begin in section I by clarifying the sort of agnosticism I have in mind, namely the second, epistemological version. In sections II and III, I explain and, to some extent, defend two assumptions that facilitate answering the main question, 'What is wrong with agnostic belief?'. I then consider what I take to be the three main answers: such a belief would be unjustified for lack of evidence (section IV); one's set of attitudes would in this case be problematically akratic or incoherent (section V); and one would be committed to a judgement-a socalled 'Moore-paradoxical' judgement-the absurdity of which reveals the irrationality of being an agnostic believer (section VI). After arguing against each of those answers, I consider, in section VII, some other features of defensible agnostic belief.

Before proceeding, a clarification about the main question is in order. There are different senses in which a state or attitude can be wrong. I will consider what is 'wrong' with agnostic belief exclusively from an epistemic perspective. This means that when we attempt to explain what is wrong with agnostic belief, we are attempting to understand a deficiency in the belief's, or in the believer's, accuracy with respect to the truth, from the subject's perspective. The relevant aspect of the subject's perspective is to be understood in terms of her evidence. So the question, clarified, is: What is wrong with agnostic belief, from an epistemic perspective, which is one that is concerned with accuracy relative to the evidence? In pursuing the question in this way, I will assume that a belief's or a believer's 'rationality' is a measure of that belief's or that believer's accuracy relative to the believer's evidence. Accordingly, the answers to the question that I will consider all take the following form: What is wrong with agnostic belief is that it is always (epistemically) irrational. 


\section{SECOND-ORDER AGNOSTICISM}

Recall that an agnostic stance on some hypothesis, $h$, is supposed to be contrary to both the stance that $h$ is true and the stance that $h$ is false. ${ }^{4}$ But the sort of agnosticism I will develop here is not defined as a failure to take a position on h's truth. Rather it is a position with respect to taking a position on h's truth. This second-order attitude is explained in general terms in this section. Though there are differing candidate attitudes that might constitute some other, neutral stance deserving of the name 'agnosticism', here I focus on one, secondorder way of being an agnostic. I will briefly mention some others, at the end of this section, for contrast.

Suppose that you believe that you have absolutely no evidence that bears on a hypothesis, so that you do not even know what probability to assign it. When you have this belief, you are not merely ignorant, since you believe that you are ignorant in the relevant respect (we surely are unwittingly ignorant about many things that we have never even considered). This belief does not yet constitute the agnosticism I want to focus on, but it is a start. Agnosticism has something to do with believing that you, perhaps that we all, are ignorant about something. To get from believing in your ignorance about something to the sort of agnosticism I want to discuss requires specifying the sort of ignorance one believes in. Roughly, the agnosticism I have in mind consists in the belief that no foreseeable source of evidence could bear on $\mathrm{h}$ sufficiently to justify belief about h. However, some further clarifications are needed, and this agnosticism needs to be further narrowed down.

First, you must believe that your total evidence is insufficient. This means you lack background (inductive or statistical) evidence about the hypothesis. For example, to borrow Russell's famous orbiting teapot example, ${ }^{5}$ you may lack direct evidence that there is a teapot orbiting the Earth, and yet possess some background evidence about what teapots are, where they come from, what it takes to launch something into orbit, whether astronauts take teapots with them and dispose of them while in orbit, and so on. This was not the

\footnotetext{
4 Rosenkranz (2007) focuses on agnosticism as a stance concerning our knowledge, whereas I will primarily be discussing justification. Otherwise, the sort of agnosticism I will focus on here is similar to the sort he discusses.

${ }^{5}$ Russell (1952).
} 
point Russell was trying to make with this example. In fact, he seemed not to recognize how our background evidence bears on the hypothesis. But it can be used to illustrate the importance of distinguishing total from direct evidence. The orbiting teapot would presumably not be a case in which you are an agnostic in the present sense, since you think that your evidence-though perhaps not direct or observational evidence-bears significantly on the hypothesis. We think we have sufficient evidence to show that it is extremely unlikely that there is such a teapot; we are atheists about orbiting teapots. ${ }^{6}$

Another way for background evidence to bear on a hypothesis, when one lacks direct evidence about it, is for one's understanding of the case to partition the possibilities in such a way as to determine a probability. For example, consider the hypothesis that the next time you roll a fair die ten times, it will land ' 6 ' each of those ten times. You understand what it is for a die to be fair, and so you 'see' that this hypothesis is very unlikely to be true. We may wish to count this as evidence against the hypothesis. Regardless of whether we count it as evidence against the hypothesis, this is a case in which, though we lack direct evidence about the hypothesis (since the rolling of the die has not yet occurred and is stipulated to be fair), we should presumably not be agnostics about it, at least not in the sense that I will be discussing. Instead, we should be fairly confident that it is false, and we should believe that this confidence is justified. Again, we lack direct evidence, but we are atheists. ${ }^{7}$

So far, I have specified that an agnostic believes that her total evidence-including her understanding of the case-fails to justify belief, or some other significant level of confidence about the hypothesis. But furthermore, an agnostic also believes that none of her current or foreseeable sources of evidence could produce such evidence about the hypothesis. For example, I currently have no evidence about whether space suits of the sort that astronauts wear at the

\footnotetext{
${ }^{6}$ Similarly, if you are agnostic, then you think that the fact that you lack direct evidence about the hypothesis does not itself confirm or disconfirm the hypothesis, since you would not expect to have any evidence about the hypothesis whatever its truth-value is. I lack space to discuss such cases here. See Sober (2009a) and Avnur (forthcoming).

${ }^{7}$ I have avoided bringing up the principle of indifference in this discussion. That principle will not be relevant to the cases I end up discussing below, and so will not help to determine a probability for the hypotheses about which I suggest we should be agnostic.
} 
space station are comfortable when worn in orbit. I've never read about this, never interviewed an astronaut, and I've never been in such a suit at the station myself. But I know that I could, in principle, find out: maybe there is or will soon be some existing literature on it, maybe I could interview a current or past astronaut, and maybe I could get hold of a suit and join some future expedition to the space station. This is not something that is likely to happen. But it is something that my sources of evidence could, in a foreseeable (though unlikely) way bear on. So I should not be agnostic about this, at least not in the sense that I will be discussing. This seems an acceptable interpretation of agnosticism. For, presumably, a philosophical agnostic about a religious hypothesis does not typically think that if we just tried harder, or investigated further, or called the right person, we would find evidence about it. At any rate, at least one recognizable sort of agnostic thinks that, in principle, we do not have access to good evidence about $h$, and this is the position I have in mind. In section III, below, I suggest that we are sometimes justified in such a stance with respect to some religious hypotheses.

As I noted above, the belief that constitutes this kind of agnosticism has a second-order character. It is about what your evidence cannot justify, or about your epistemic situation with respect to the relevant hypothesis. Thus, I call it 'second-order agnosticism'. Specifically, second-order agnosticism about some hypothesis is the belief that no (first-order) doxastic attitude about the hypothesis can be justified by the evidence (as described by the specifications above). I understand doxastic attitudes to include at least belief and disbelief (i.e. belief not-), as well as degrees of confidence about the relevant hypothesis. The 'can' is meant to signify that this applies to what your current and foreseeable sources of evidence could supply (it is not meant to imply that it is a necessary fact that you will always lack evidence from any possible source). I will discuss one important implication of the possibility of there, someday, somehow, being evidence in the last section, section VII. But for the most part it will not matter for my main question, which concerns agnostic belief. Finally, note that second-order agnosticism is a belief, and as such it could turn out to be false.

Second-order agnosticism is worth distinguishing from other attitudes that might be considered agnostic, but which are more direct or first-order. Clearly it is distinct from any first-order attitude since it is a second-order attitude, but, further, first-order agnosticism does not 
necessarily commit one to second-order agnosticism. There are hypotheses and evidential situations such that some first-order type of agnosticism may be appropriate while second-order agnosticism is not (and vice versa). Here are a few instances of this.

First, simply having no attitude about $\mathrm{h}$ might be interpreted as agnosticism about h. But we have this (non-)attitude about hypotheses which we have never even considered, and clearly we do not and should not believe second-order agnosticism about hypotheses we have never even considered.

Second, having a .5 , or middling, degree of confidence in a hypothesis might be thought to be a sort of agnosticism about it. But one might have this attitude on the basis of evidence that is equally weighted for and against the hypothesis. If so, then second-order agnosticism would not be appropriate, since evidence could bear on the hypothesis. That is, one's sources of evidence are such that they could produce evidence sufficient for justified belief (say, in the absence of the other, competing evidence that one actually happens to have).

Third, one might think that considering, and then withholding, belief about a hypothesis constitutes a type of agnosticism. But one could be in this state without properly being a second-order agnostic. For example, one might withhold belief while the investigation is ongoing, while one is considering the weight of various items of evidence, or watching the evidence come in. In such a case, of course one may well believe that one's sources (or foreseeable sources) could sufficiently bear on the hypothesis, so one is not a second-order agnostic.

So far, I have suggested that the having of various first-order 'agnostic' attitudes towards a hypothesis does not commit one to second-order agnosticism. My main question now concerns being a second-order agnostic while not withholding belief in the relevant hypothesis. That is, is it necessarily irrational to be a second-order agnostic about $h$ while having a belief or confidence one way or another about $h$ ? I am calling this combination of attitudes-secondorder agnosticism about a hypothesis and belief or confidence about that hypothesis-agnostic belief.

Before considering the question, though, two assumptions must be made, explained, and defended. In section II, I consider whether agnostic belief is even possible. In section III, I consider whether second-order agnosticism itself can ever be justified, with respect to some religious 
hypotheses. After that, in sections IV-VI, I will consider whether agnostic belief is always irrational.

\section{FIRST ASSUMPTION: AGNOSTIC BELIEF IS POSSIBLE}

In considering the rationality of agnostic belief, I will assume that agnostic belief is logically, conceptually, and psychologically possible. I think that these assumptions are plausible but I will not have space to argue thoroughly for that. Instead, I will just make the assumptions explicit and gesture towards their motivation. After this, I will also suggest that these assumptions may not really be necessary, though they are useful.

I assume that agnostic belief is logically possible. This seems a safe assumption because there is no formal contradiction in attributing to some subject both second-order agnosticism and belief: the belief that constitutes second-order agnosticism about $h$ is distinct from belief that $h$, by definition. Furthermore, the truth of second-order agnosticism about $h$ is compatible with both the truth and the falsity of $h$. So there seems to be no reason to hold that it is logically impossible for someone to hold an agnostic belief.

I assume that agnostic belief is conceptually possible in the sense that the concept of belief does not rule out agnostic belief. Some hold that, in order to be a belief, an attitude must be susceptible to change due to new evidence. ${ }^{8}$ But this account of belief does not make agnostic belief impossible. For, it does not follow, from one's being a second-order agnostic about $h$, that one's attitude towards $h$ is not susceptible to evidence, even by one's own lights. For instance, if some unforeseeable source of evidence were to arise, the agnostic believer's belief that $\mathrm{h}$ might change, and she would no longer be a second-order agnostic about h. For example, if an agnostic believer learns that her second-order agnosticism is mistaken, and, say, there is actually evidence against the hypothesis, she could (presumably would) drop her belief that $h$. And, to take another example, even if

\footnotetext{
${ }^{8}$ For example, Gendler (2008) contrasts belief in this way with what she calls 'alief', and Van Leeuwen (2014) contrasts belief in this way with what he calls 'religious credence'.
} 
one's second-order agnostic belief about $\mathrm{h}$ is true, and no current or foreseeable source of evidence can bear on $\mathrm{h}$, it may still be true that, supposing that one were to get evidence (as is impossible in this case), one would change one's attitude about $h$. The disposition to be sensitive to evidence might be there even in the absence of any possible evidence. The agnostic belief is, in that case, much like a fragile glass in a world filled with pillows. ${ }^{9}$

Granting that agnostic belief is logically and conceptually possible, there is still the question whether it is (humanly) psychologically possible. That it is psychologically possible is really the main assumption, since this possibility entails that agnostic belief is both logically and conceptually possible. It is not only the strongest assumption, but also the most complex and contentious. I will discuss this assumption in more detail, below, when discussing akrasia. For now, I will simply assume that agnostic belief is psychologically possible and point out a few things about it.

First, notice that second-order agnosticism is about what can be justified by the evidence. So, anyone who thinks that, eventually, we must believe something without evidence because evidence must come to an end, must hold that agnostic belief is psychologically possible. Some popular forms of foundationalism seem committed to this view: ${ }^{10}$ they think that it is possible to believe something when one also believes that there is no evidence for it. Similarly, those who think it is possible (though perhaps irrational) to believe something on blind faith already think it is possible to be an agnostic believer. Less obviously, one might think that cases of self-deception, in which a person believes that evidence does not justify some belief and yet still holds that latter belief, provide a third type of psychologically real case.

Second, agnostic belief has been assumed to be psychologically possible throughout much of the history of philosophy, at least by some prominent philosophers. On one interpretation, Kant's 'practical postulates' are beliefs (or, at least, commitments) one could have

9 See Ribeiro (2011) for discussion, historical overview, and rejection of the view that akratic beliefs are impossible.

${ }_{10}$ Wright (2004) and White (2006) have defended this sort of view in the context of scepticism about the external world. Ribeiro (2011) holds that agnostic belief is actual in the same context, but without committing to foundationalism. Others, such as Plantinga (2000), have rejected evidentialism, and are also committed to the psychological possibility of agnostic belief, in the context of religious belief. 
while recognizing that reason does not support them. ${ }^{11}$ Similarly, Hume seems to have held both that some beliefs cannot be supported by any reason or evidence and that having such beliefs is naturally unavoidable. Sextus arguably also held that we must assent to things without holding that there is any (unopposed) evidence for them. So this assumption is in some good company.

Finally, note that, even if the assumption is wrong, and we are not able, psychologically, to hold agnostic beliefs, we may still ask an abstract, ideal, normative question about it. That is, we could still ask whether, were it possible to have such a combination of attitudes, that would be rational. This would not be an unprecedented sort of question, and it can still be an important one in this case. It is not unprecedented because, for one example, Bayesian or 'formal' approaches to epistemology idealize beyond what is psychologically possible. It is held, for example, that being logically omniscient is rationally ideal, despite the fact that this is psychologically impossible. ${ }^{12}$ It is still interesting to consider the rational status of agnostic belief, even if it turns out to be psychologically impossible, because that would shed light on the status of our actual state when we are second-order agnostics about something. That is, the status of agnostic belief can help to determine what we take the status of agnostic non-belief to be. It may, for example, turn out to be epistemically no better than agnostic belief, even if agnostic belief is psychologically impossible.

\section{SECOND ASSUMPTION: SECOND-ORDER AGNOSTICISM CAN BE JUSTIFIED}

So far, I have assumed that agnostic belief is possible. I will also assume that there are situations in which it is rational, or justified, to be a second-order agnostic in the first place. This is a helpful assumption because such circumstances, in which second-order agnosticism is justified, will presumably place some constraints on one's first-order attitude about the hypothesis in question. Furthermore, it is worth

11 See Chignell (2007).

12 See Christensen (2004) for some discussion of this. 
considering cases in which second-order agnosticism is justified in order to further motivate our question about agnostic belief. After all, who cares if it is rational to believe something that one is second-order agnostic about if it is never rational to be second-order agnostic about anything? Finally, note that it is unnecessary to argue, or even assume, that all or even all standard religious hypotheses are such that secondorder agnosticism is sometimes justified about them. The question is whether agnostic belief is always irrational. If it can be shown that one significant (i.e. not overly contrived) example of justified second-order agnosticism might in fact be non-wrongly held in conjunction with a belief in the hypothesis, this will show that the answer is 'no, it is not always wrong to be an agnostic believer'. This may well shed light on agnostic belief in general.

In discussions of religion, an obvious and classic hypothesis about which agnosticism seems appropriate is one according to which there is a God that is transcendent in the sense that we cannot get evidence for it during our lives in this world. The existence of this God would matter to us, presumably, at least in part because it would make some sense of our existence, and perhaps hold some promise of an afterlife for us. One can even leave some room for interaction between us, the creatures of this world, and such a God, in the form of miracles that have happened long ago or in faraway places. Such miracles, though, must not have the capacity to provide us with evidence for such a God's existence, or else belief, rather than second-order agnosticism, will be justified by the evidence. Thus, the requisite transcendence is epistemological rather than strictly metaphysical; we should think of this sort of hypothesis as one according to which an epistemically transcendent God exists. This seems, by definition, something about which we are justified in being second-order agnostics.

A similar hypothesis posits some form of divinity or other, without specifying that it is a god. We can think of this as the hypothesis that an epistemically transcendent divinity exists. By hypothesis, we can have no evidence either for or against it. So, it seems that secondorder agnosticism is justified. ${ }^{13}$ On such hypothesis is James' religious hypothesis in The Will to Believe:

13 Do explanatory considerations of simplicity and elegance tell against this hypothesis? I think not, but I cannot defend that here. See Sober (2009b). 
the best things are the more eternal things, the overlapping things, the things in the universe that throw the last stone, so to speak, and say the final word... [and] we are better off even now if we believe [this] to be true. ${ }^{14}$

James famously held that the 'intellect' is silent on whether we should believe this hypothesis, in the sense that none of our evidence could possibly indicate whether it is true (at least independently of a belief we may have in it). Another, similar hypothesis can be found in Schellenberg's work, under the titles of 'Ultimism'- 'there is a metaphysically and axiologically ultimate reality (one representing both the deepest fact about the nature of things and the greatest possible value), in relation to which an ultimate good can be attained ${ }^{15}$ - and 'T-ism'-'Reality is transcendent-more than or other than the arena of mundane events or ... anything physical or natural'. ${ }^{16}$ It is hard to see how our current or foreseeable sources of evidence could bear on such hypotheses. So, presumably, second-order agnosticism about such hypotheses could be justified.

One might want to argue that second-order agnosticism is also justified with respect to more traditional theistic hypotheses. And there may also be secular hypotheses about which second-order agnosticism is justified. ${ }^{17}$ In assuming that some such hypotheses are plausible targets for second-order agnosticism, I do not mean to make any contribution to a debate about whether this is so. For example, I will not make any attempt here to contribute to the theological tenability of an epistemically transcendent yet personal God. ${ }^{18}$ Rather, I mean only to give some, albeit vague, content to the idea that there are some hypotheses about which second-order agnosticism is justified. My main question concerns the status of agnostic belief, and it will not matter, in what follows, what the content of the belief, or the hypothesis in question, entails. What matters is that one is justified in being a second-order agnostic about some hypothesis.

14 James (1897 [1896]).

16 Schellenberg (forthcoming), p. 9.

17 Examples of secular hypotheses include hypotheses about the positions of particles so far away that no information about them is possible at this point in the universe's evolution, and perhaps some sceptical hypotheses about which, arguably, we can never get any evidence.

${ }^{18}$ See, for example, Schellenbeg's most recent book on the problem of divine hiddenness (2015). 
What if one insists that there is no hypothesis about which secondorder agnosticism is justified? I have two points to make about this insistence. First, the idea that second-order agnosticism is never justified for any hypothesis is implausible for various reasons. Here are a few. First, setting the largely rejected logical positivist perspective aside, it is hard to imagine why one would insist that it is impossible for something to be true while we lack evidence for it, in principle. Second, it seems likely that there are some such hypotheses, since accuracy per se is not strictly a constraint upon evolution; there is no reason to think that our evolution requires accurate beliefs about all aspects of reality, but only those that are relevant to our satisfying the requirements of efficient reproduction. Third, there seem to be uncontroversial examples aside from the overtly 'religious' ones discussed above. Consider, for example, the continuum hypothesis. Plenty of other, widely recognized examples exist in the literature. ${ }^{19}$

The second point to make is that, if it turned out that there is no hypothesis about which second-order agnosticism is justified, that would be a remarkable and interesting fact. In order to appreciate how astonishing it would be if no hypothesis were worthy of our second-order agnosticism, we should consider what the consequences would be if some hypothesis were worthy. So, if for no other reason, we should still be motivated to figure out what second-order agnosticism entails.

From here on, I will continue to use ' $h$ ' as a stand-in for some hypothesis about which second-order agnosticism is justified. Those who think there is some such hypothesis should understand ' $h$ ' accordingly, and those who think there is no such hypothesis can use ' $h$ ' hypothetically, in order to investigate the significance of their view.

\section{FIRST ANSWER: AGNOSTIC BELIEF GOES AGAINST RATIONAL REQUIREMENT TO WITHHOLD JUDGEMENT}

One might think that agnostic belief is irrational because the only justified first-order attitude to have in the absence of evidence is 
withholding belief, or not believing either way. In that case, agnostic belief is unjustified in the same way that any belief held in the absence of evidence is unjustified. Here it will be helpful to assume, for the sake of argument, that second-order agnosticism is not only justified but also true in this case. This will simplify the discussion by eliminating the need to address whether, if one has a false belief in secondorder agnosticism about $h$, one's belief that $h$ is still unjustified. ${ }^{20}$ So, let us consider the following claim: granted that a subject correctly believes second-order agnosticism about $\mathrm{h}$, believing that $\mathrm{h}$ (or not- $\mathrm{h}$ ) is unjustified, and that explains what is wrong with agnostic belief that $h$.

I have three independent objections to this claim. The first two concern the claim that belief that $h$ is in this case unjustified: (a) this is not always so obviously plausible; and, (b), if it is true it is insignificant. My third objection is that: (c) even if it were true and significant that believing $h$ is unjustified, this does not adequately explain what is wrong with agnostic belief.

\section{(a) Is Agnostic Belief Really Unjustified?}

How plausible is it that, given that one's second-order agnosticism about $\mathrm{h}$ is correct, one's belief that $\mathrm{h}$ is unjustified? Many, perhaps most, epistemologists are foundationalists. According to some versions of that view, some beliefs are justified even though they are not justified by any evidence or by any further justified belief. Those are the foundational or 'basic' beliefs. Of course there are many different versions of this view, and this is usually offered as a solution to some sceptical problem. But the point is that many epistemologists are already committed to the idea that at least some beliefs are justified but not by any evidence. Without the further stipulation that they are mistaken, or that $\mathrm{h}$ cannot be one of these basic, justified beliefs, it does not follow from second-order agnosticism about $h$ that $h$ is unjustified. $^{21}$

The observation that, at least according to some theories, evidence is not necessary for justification leaves open the possibility that

20 See Horowitz (2014) on higher-order defeat.

21 In Avnur (2012a), I argue that justification without evidence is a problematic notion. I have also rejected the seeming analogy between anti-sceptical beliefs and religious beliefs, even granting that they both lack evidence (2012b). 
agnostic belief that $\mathrm{h}$ is justified. Since my aim is merely to argue that the claim that $\mathrm{h}$ is unjustified does not itself explain what is wrong with agnostic belief, we can set aside whether such other theories are true. $^{22}$ As long as we lack decisive objections against all versions of foundationalism that could apply to h, we have no decisive reason to regard $h$ as unjustified.

\section{(b) Would It Matter That H Is Unjustified?}

Set aside the reservations expressed above and grant, for the sake of argument, that agnostic belief that $h$ is unjustified. How exactly would this explain what is wrong with believing h? The answer might initially seem obvious: it is wrong because it is unjustified. However, there are different ways for a belief to lack justification. One way is for one's total evidence to tell against $h$, or for it to make $h$ relatively unlikely. Given our definition of second-order agnosticism, this is not the case with $h$. Rather, in the case of $h$, evidence does not bear at all on the likely truth of $\mathrm{h}$. There is no way, on the basis of consulting my current and foreseeable sources of evidence, to give a non-arbitrary verdict on the likelihood of $h$. So if belief that $h$ is unjustified, it is not unjustified because of some verdict on its probability. Rather, it is unjustified because no probability assignment can be justified by my evidence in general (at least from any foreseeable source).

This is important because there is a difference between a belief's being unjustified and a belief's being in some sense forbidden by evidential considerations. If the total evidence tells against the truth of $h$, then believing $h$ goes against the evidence, and can be said to be forbidden by evidential considerations. But if my sources of evidence are totally silent on whether $h$ is true, is belief that $h$ also forbidden? It is forbidden only given some additional principle, to the effect that it is always forbidden to believe something unless the evidence tells in favour of it. We are currently granting that belief that $h$ is unjustified, so we are in effect granting some such principle. But, even given the principle's truth, it should be noted that when a belief's status as unjustified depends solely on some a priori principle of justification, the status should be taken with a grain of salt, for two reasons. 
First, there is the familiar Jamesian point that the aim of avoiding error is not intrinsically worthier than the aim of attaining (interesting) true beliefs. If evidence is silent on $h$, then the question whether it is wrong to believe $\mathrm{h}$ comes down to which of the two Jamesian aims is more valuable. Another way to see this is that one can be committed to accuracy, and thereby follow the evidence where it leads when it leads somewhere, and still endorse the policy of believing when evidence is entirely silent. By taking on the belief that $h$, one does not compromise one's accuracy at all, since there is no reason (or evidence) to think that $\mathrm{h}$ is less likely than not. The idea that we should be on guard against error more than we should be adventurous in our believing is a popular one among philosophers, to be sure. The Jamesian point is that this is not itself a position that is based on evidential considerations. Since I am granting that belief that $h$ is unjustified, I must draw a slightly different lesson from this Jamesian idea: believing $\mathrm{h}$ may be unjustified, but this is merely because we are prejudiced against error, because we take on some a priori principle that biases us towards non-belief, instead of favouring potential true beliefs-and it is certainly not because believing that $h$ goes against any specific evidence or the total evidence. Given this fact about the unjustifiedness of $h$, and given that one's primary consideration is accuracy rather than some particular version of accuracy (such as primarily avoiding error), one should not mind so much if, in this case, one's belief is unjustified. It merely counts as unjustified because of the way we (according to what we are presently granting) count justification, not because accuracy or evidence itself tells against believing.

A second way to see the insignificance of being unjustified in believing $h$ is to consider some alternative notions of justification. We are currently assuming that believing $h$ is unjustified. But suppose we invent a new notion, justification2. Justification2 is just like justification, and gives all the same verdicts in all the same evidential situations as justification does, except when evidence is silent on a proposition, in the way it is when second-order agnosticism is true of it. In such cases, while we are granting that believing is unjustified, we can stipulate that believing is not unjustified2, and it is also not justified2. Instead, justification2 is entirely silent on whether to believe. We can say that believing is a-justified2, rather than unjustified2. So, the only difference between justification and justification 2 is that, when evidence is silent about a proposition, justification forbids 
belief while justification2 says nothing about belief (or non-belief, or disbelief). Now consider the question why we should care more about justification than justification2.

Justification and Justificaiton2 tell us the same exact thing whenever second-order agnosticism is false about a proposition, so in all ordinary cases, there is no difference between the two concepts. The only difference is that, when evidence is silent on an issue, justification2 has nothing to tell us. It 'permits' belief only in the sense that it does not forbid it-similarly, one might say that it is morally 'permissible' to wiggle your toes right now, not because morality supports it, but because morality does not say anything at all about it. This is not, then, a substantive verdict on whether to believe. Justification 2 is simply silent when the evidence is silent. If we are concerned solely with truth and accuracy in belief, there does not seem to be any reason to prefer justification to justification2; there is no accuracyrelevant advantage to following the rules of justification, rather than of justification2. Therefore, given that our concern is solely with truth and accuracy, it does not matter that believing $h$ is unjustified, given that it is also a-justified2. In other words, when the two concepts diverge, there is no good, epistemic reason to go along with justification rather than justification2. One way to understand this is along Jamesian lines: the aspect or principle of justification that forbids belief in the case of $h$ does not itself derive from the values of truth or accuracy. Rather, it derives from a preference for avoiding error over believing adventurously. It is, in that sense, arbitrary with respect to accuracy.

If what I have just argued is correct, then even if we grant that agnostic belief is unjustified, this should not matter much. The lack of justification, or even the forbiddenness of belief that $\mathrm{h}$ according to our notion of justification, would not explain why it is really, meaningfully wrong to hold an agnostic belief. For, the only thing wrong with agnostic belief, on the current proposal, is that it happens to be unjustified, given the notion of justification that we happen to employ. But we could have employed a different notion of justification that did not have this implication, and which would have been equally faithful to our valuing truth and accuracy in belief.

Objection: epistemic justification, and rationality, cannot possibly be arbitrary in this way. It is impossible for something to be arbitrarily justified or unjustified, from the perspective of accuracy, because justification is precisely the notion we use to track accuracy (from a 
given subject's perspective). So, something must be wrong with the argument above.

Reply: We have a choice here. If we accept this objection, we should take it as an objection also to the assumption that it is unjustified, or irrational, to believe $\mathrm{h}$ in this case. If so, then its being unjustified to believe $h$ does not explain what is wrong with believing $h$, since the belief is not unjustified. That is, the objector must take the argument about rationality 2 as a reductio of our opening assumption that belief that $\mathrm{h}$ is unjustified. But we need not take a stand on whether the objector is right. The argument presented here leaves us at least with this disjunction: either belief that $\mathrm{h}$ is not unjustified, or else it is unjustified only because we happen to appeal to justification rather than justification2, and this is an arbitrary decision. The objection eliminates the second disjunct. But, regardless of whether it succeeds, we cannot explain what is wrong with believing $h$ by appealing to the claim that it is unjustified (for, according to the objection, it is not unjustified, and otherwise it is merely arbitrarily unjustified).

\section{(c) What Does Agnosticism Have to Do with It?}

My first point, (a), was to cast some doubt on the idea that agnostic belief is always unjustified. My second point, (b), was that even if it is unjustified, this is not a significant fact about agnostic belief, given the source or basis of its being unjustified. My third point is entirely independent of the first two, and it can appeal even to those who think that (a) and (b) are entirely wrong-headed. Our sense that there is something wrong with agnostic belief that $h$ is not merely the sense that belief that $\mathrm{h}$ is unjustified. There are many ways for a belief to be unjustified even in the absence of a further, higher-order belief about it. Surely, at least part of what is wrong with agnostic belief that $h$ is the combination of believing both that there is no evidence for $h$ and that $h$ is true. The second-order belief surely has something to do with what is wrong here. But the claim that the belief that $h$ is unjustified does not imply anything about there even being a second-order belief. In other words, insofar as we think that possessing the second-order belief-being an agnostic-is significant to what the agnostic believer is doing wrong, the suggestion that belief that $h$ is unjustified does not satisfactorily explain what is wrong. The distinctive problem with agnostic belief has not yet been identified. 


\section{SECOND ANSWER: AGNOSTIC BELIEF IS AN AKRATIC STATE}

The phenomenon of akrasia is familiar in the practical sphere: it is, very roughly, when you do what you think you should not do. Philosophers have realized that there is a doxastic analogue: when you believe what you think you should not believe. Is this what the agnostic believer does, and is it always irrational?

The crucial question here is what, exactly, are the two conflicting states that the agnostic believer is purportedly in? One of them is belief that h. But what is the further state that clashes with this belief in a manifestly irrational or incoherent way? As we saw above, even assuming second-order agnosticism is correct about $h$, and that the subject believes second-order agnosticism about $h$, it is not obvious exactly what the subject should think about the status of h. Given the considerations offered in section IV(a) and (b), we cannot simply assume that the agnostic thinks that one should not, all things considered, believe h. For, in the first place, it is not obvious that second-order agnosticism entails that belief that $\mathrm{h}$ is unjustified, and, in the second place, even if it did entail that believing $h$ is unjustified, this seems an arbitrary verdict from the perspective of accuracy. The only uncontroversial verdict about belief that $h$ is that it is not justified on the basis of evidence, or that it is not the case that you should believe $h$. We cannot assume that every agnostic believer believes much more than that about the status of belief that $h$.

In light of the fact that the most we can say on behalf of the agnostic is that believing $h$ is not justified, the following pairs of states are the most straightforward candidates for akratic description of the agnostic believer (in first person, in order to display the potential incoherence):

(1) Believing that I am not epistemically justified in believing $p$, and believing $\mathrm{p}$

(2) Not believing that I am epistemically justified in believing p, and believing $\mathrm{p}$

These are situations in which one believes without justification, not against it. Consider a practical analogy. Suppose that I have no justification-and, let us specify, this is because there is no reasonto wiggle my toes right now. Suppose that I wiggle my toes. Is this akratic or incoherent? Presumably not. For, it is not the case, right 
now, that there is some reason to refrain from wiggling my toes (or at least I do not believe there is). So the bare fact that I do something while thinking that there is no justification to do it, as in (1), or failing to think that there is justification to do it, as in (2), is not enough to make me incoherent, or irrationally akratic.

In order for a higher-order state to clash with a belief in an akratic way, the higher-order state must weigh against, or negatively assess, the belief. But, since evidence is silent on $\mathrm{h}$ (in a way, recall, that does not support even a 50/50 assessment of h's chances) it is impossible that such a higher-order state is justified in this case. Or, more precisely, if it is justified, it is only arbitrarily, and so not importantly, justified. A straightforwardly akratic, or internally incoherent, state is not entailed by agnostic belief, at least not without further controversy, given the discussion in section $\operatorname{IV}(\mathrm{a})$ and (b).

One might suspect that too much here rests on my previous objections, in section IV, to the view that belief that $\mathrm{h}$ is unjustified or forbidden. My objections were admittedly not meant to be conclusive. Rather, they purported to show that it is not clear whether belief that $h$ is forbidden, and that if it is forbidden, it is only arbitrarily so. An agnostic believer might be convinced by my arguments, and so fail to believe that her own belief is significantly forbidden. So she might not be akratic. Still, one might think that it is also not clear whether agnostic belief should entail akrasia. A more explicit illustration of the combination of attitudes at issue here, and an assessment of the combination in light of considerations of accuracy, will be helpful.

Goldman has usefully distinguished 'ex ante' justification from 'ex poste' justification. ${ }^{23}$ One has ex poste justification when one's belief is itself supported by evidence. One is ex ante justified in believing $\mathrm{p}$ when $\mathrm{p}$ is the right thing for her, the subject, to believe. Whether one has ex ante justification, then, depends on the rest of the believer's states and beliefs. The idea that akrasia is irrational, and that therefore the agnostic believer is irrational, is a matter of irrationality ex ante, presumably. For it is in virtue of holding the combination of beliefs, not some single belief type considered in isolation, that the subject is said to be akratic. The view currently being considered is presumably that the agnostic lacks ex ante justification because the agnostic 
believes that her belief that $\mathrm{h}$ lacks evidential support, so presumably belief that $\mathrm{h}$ is not the right thing for her to believe. But now notice that this ex ante irrationality, at least in this case, is not epistemic, or related to accuracy. For, all the agnostic believer has done to deserve to be called irrational is add the belief that $h$. And, by stipulation, the agnostic can have no indication whatsoever that $\mathrm{h}$ is likely to be false. So the agnostic went from rational to irrational by adding a belief which does not affect her overall accuracy from her evidential perspective. So the akrasia involved here is not epistemically irrational, or irrational from the perspective of truth and accuracy. It is perhaps not an ideally coherent state to be in, but that would not explain why being an agnostic believer is epistemically wrong.

The point can be summarized as follows. Consider a system of beliefs that is coherent and includes the belief in second-order agnosticism about $h$. Adding the belief that $h$ is true (or the belief that $h$ is false) does not make this system incoherent. If it degrades the system, it does not do so epistemically, since relative to, or internal to, the system there is no believed indication that believing $h$ decreases accuracy. There is no epistemic inconstancy in such a system since belief that $h$ need not be forbidden according to the system, even if it is not supported or justified by the system.

One final note about knowledge will be helpful here. Some philosophers $^{24}$ have suggested that believing something commits one to having knowledge of it, or that knowledge is the norm of belief. The second-order agnostic holds that $\mathrm{p}$ is unknowable, so, according to the knowledge norm of belief, agnostic belief is irrational. ${ }^{25}$ Interpreted as a view about epistemic rationality of belief, the knowledge norm seems implausible, as others have argued. ${ }^{26}$ Though I lack space to discuss the debate at length here, one can appreciate the initial difficulty for the knowledge norm of belief by considering simple, justified, false beliefs. False justified beliefs are not knowledge, but they are still justified beliefs. For example, I could have very good evidence that my wife is a Catholic, but it could turn out that she is not. Perhaps she has been carefully hiding her true religion from me for years. If that happens, I was still justified, by all that evidence, in

\footnotetext{
${ }^{24}$ For example, Williamson (2000); Owens (2000); and Huemer (2007).

25 Thanks to Paul Hovda for bringing the knowledge norm to my attention in this connection.

${ }^{26}$ For example, Littlejohn (2010) and Hawthorne, Rothchild, and Spectre (2016).
} 
believing she was Catholic. Given all the evidence I had, it seems it would have been irrational, from an epistemic point of view, not to believe that she is Catholic! So, although I did not know she is Catholic, it was rational for me to believe that she is Catholic. The knowledge norm seems, prima facie, false. Note also that similar views about assertion, ${ }^{27}$ though more plausible, are irrelevant to belief, in the absence of further argument. I discuss the relation between asserting and believing in section VI, in connection with Moore's paradox.

\section{THIRD ANSWER: AGNOSTIC BELIEF COMMITS \\ ONE TO A MOORE-PARADOXICAL JUDGEMENT}

Agnostic belief may still seem to involve some sort of inconsistency, because it entails a recognition that evidence fails to support what one believes. In section $\operatorname{IV}((a)$ and (b)) I suggested that this absence of evidential support for one's belief-that is, the second-order agnosticism about $\mathrm{h}$-does not necessarily make believing significantly unjustified. And, in section V, I argued that having both agnostic and believing attitudes is not necessarily epistemically irrational. But if one has both attitudes, and one is conscious of this, then one is in a position to judge that one is in both attitudes. This judgement can be performed to oneself or to others, in the form of an assertion, affirming that one does not endorse (or think there is evidence for) a belief that one has. The idea considered in this section is that this self-conscious judgement leads, in two steps, to an explanation of what is wrong with agnostic belief. The first step is to claim that this judgement, to the effect that one holds both agnosticism and belief about the same hypothesis, is odd or, worse, absurd. The second step is to claim that the absurdity of judging that you are an agnostic believer shows that there is something wrong with being an agnostic believer.

However, both steps are independently problematic, and both would need to be correct in order for this approach to succeed.

27 For example, Unger (1984); Williamson (2000); and Lackey (2007). 
I will frame this discussion in terms of so-called 'Moore-paradoxical sentences'.

\section{(a) Is a Moore-paradoxical Sentence Produced by Agnostic Belief Absurd?}

Moore-paradoxical sentences are conjunctions that clearly could be true and yet it is absurd, perhaps incoherent, for someone to assert or judge them to be true. ${ }^{28}$ So perhaps one way to bring out what seems irrational about agnostic belief is to put the two elements, the agnosticism and the belief, together into a conjunction of the sort that gives rise to Moore's paradox. In what follows I use the term 'judge' to mean 'either assert to others or think to oneself'. To take the standard example, it could be true about someone, $\mathrm{S}$, that

It is raining and $S$ does not believe that it is raining

But it is absurd for $S$ to judge

It is raining and I do not believe that it is raining.

The puzzle is to explain why the second conjunction is absurd, given that, as we just saw, it could be true. I will not summarize the vast literature on this here. But it is possible to determine whether this will settle our question by considering some initial rough ideas about the paradox. It is tempting to say that the first-person judgement above seems absurd because, in the first conjunct, $S$ seems to express or imply (among other things) that $S$ believes that it is raining; and the second conjunct specifies that $S$ does not believe that it is raining. That is one solution to this version of Moore's paradox, if it correctly explains what is wrong with judging the conjunction.

In order to gain insight into agnostic belief, we need to consider other, epistemic variations of the paradox, in which an assertion is conjoined with an epistemically relevant claim. ${ }^{29}$ For example,

It is raining and $S$ does not know that it is raining might well be true, but

It is raining and I do not know that it is raining

28 See Coliva (2015) for a recent discussion of Moore's paradox.

29 See Huemer (2007) for discussion of epistemic versions of Moore's paradox. 
seems very odd. One natural explanation for this is that, if you do not know that it is raining, you should not assert that it is raining in the first conjunct. But, is the agnostic believer committed to any such, absurd judgement? I think not.

The agnostic believer's agnosticism implies that she does not know whether $\mathrm{h}$ is true. So she presumably is willing to judge that she does not know that $\mathrm{h}$. This matches the second conjunct above ('I do not know that it is raining'). But what about the first conjunct? The agnostic believer is not necessarily an agnostic asserter, to others or to herself in thought. That is, it is consistent with being an agnostic believer that one also does not, and should not, make an unqualified judgement that $h$.

What is the relation between believing $h$ and being willing to judge, without qualification, that $h$ ? It is often noted that, when one asserts something, one is expressing belief in that thing. That is, according to one standard theory of language, one of the main functions of assertion is to communicate beliefs. But it does not follow that one should be willing to assert anything that one believes. And, clearly, asserting ' $h$ ' does not merely or only express a belief that $h$. It does other things too. For example, according to the knowledge norm of assertion, it expresses a commitment to knowing that $p .^{30}$ That is a good explanation of why ' $p$ and I do not know that p' sounds so odd. It could be this other stuff that an assertion that $h$ expresses, not the mere belief in $\mathrm{h}$, that clashes with the second conjunct, 'I do not know that $h$ '. If so, then the mere belief in $h$ does not clash with the judgement that one does not know that $h$.

To appreciate this point, notice that there is more than one way to communicate, or to judge, that one believes something besides asserting it. One can say, or say to oneself, that one believes it. ${ }^{31}$ One can say 'I believe that $\mathrm{p}$ ' with the aim of communicating that one believes that p. (That is not to say that this is the only thing one can communicate with 'I believe p'.) And notice that

I believe that $\mathrm{p}$ but I do not know that $\mathrm{p}$

30 See Unger (1984) and Williamson (2000).

31 See Moran (2001), pp. 100-7, on this point; and Chislenko (2014) for some discussion. 
does not sound so bad. In fact, however that conjunction initially strikes you, you should not, on reflection, think it is absurd. Consider the fact that the following sounds absurd:

I know that $\mathrm{p}$ but maybe $\mathrm{p}$ is false

However, this assertion does not sound absurd:

I believe that $\mathrm{p}$ but I might be wrong about that

and nor does this assertion:

I believe that $\mathrm{p}$ but maybe $\mathrm{p}$ is false

If 'I believe that p' does not clash with 'I might be wrong about that', then 'I believe that $\mathrm{p}$ ' cannot commit you to 'I know that p', since that does clash with 'I might be wrong about that'. Therefore, 'I believe that $\mathrm{p}$ and I do not know that p' must not be Moore-paradoxical, at least not in virtue of the states that the two conjuncts directly describe (namely, agnostic belief). So whatever explains the oddity of

\section{$\mathrm{P}$ and $\mathrm{I}$ do not know that $\mathrm{p}$}

it is not that believing that $\mathrm{p}$ commits you to knowing that $\mathrm{p}^{32}$

Some ${ }^{33}$ hold that there is a sort of belief, 'outright' or 'categorical' belief, which commits you to practical certainty. Briefly, they think that when you categorically believe something, this ends the inquiry into it, and the possibility that it is false is off the table (absent new, further evidence that dislodges your categorical belief). You can therefore appropriately assert it, without qualification, in your own thinking and to others. So if the agnostic believer categorically believes $\mathrm{h}$, then it seems she is indeed committed to the judgement ' $\mathrm{h}$ and I do not know that h', which we are granting is an absurd judgement.

However, I doubt that what we usually mean, in ordinary English, by 'believe' is categorical belief, so I am inclined to treat this view with a huge grain of salt. Even Huemer acknowledges, for example, that 'I believe that $\mathrm{p}$, but $\mathrm{p}$ might be false' does not sound problematic, or at any rate is not Moore-paradoxical. ${ }^{34}$ His explanation is that, when we

32 See Hawthorne, Rothchild, and Spectre (2016) for discussion of similar sorts of Moore sentences, also leading to the conclusion that the norm for assertion is stronger, or more demanding, than the norm for belief.

33 For example, Owens (2000) and Huemer (2007).

34 Huemer (2007), p. 153. 
describe ourselves as believing something is this case, we have in mind a non-categorical belief; we have partial belief in mind, or a belief that consists in having a high enough degree of confidence.

Even ignoring the question of what the ordinary English 'believe' means, we can set aside categorical belief. For our purposes, it would be interesting enough if the following state turned out to be not irrational: having a high degree of confidence in $h$ while thinking that $h$ is unknowable because there is no evidence for it (in the sense that second-order agnosticism is true about it). This is not a 'retreat' to a less interesting view than was originally advertised. For one, merely being confident in $\mathrm{h}$, or thinking that $\mathrm{h}$ is probably true, does what we usually take beliefs to do. It can explain someone's actions, for example: he climbed the tree because he was pretty confident that there was gold in the bird's nest. Categorical belief is not required for explaining behaviour in the way that beliefs as we usually think about them do. Second, most other beliefs are just like the non-categorical agnostic belief with respect to our unwillingness to unqualifiedly assert their content. For example, when I am discussing with someone why I believe, or the reasons for believing, that the climate is changing, I am not going to just assert, without qualification, that it is changing, even though I do believe that the climate is changing. Similarly, I believe that I will not die completely broke. But given that I think there is some small chance that I will die broke, I will not just use the premise that I will not die broke when thinking about my children's future. Instead, I am going to use the premise that most likely I will not die broke, or maybe that I will not die broke with the qualification that I am assuming the worst-case scenario will not happen.

To sum up, I grant for the sake of argument that the epistemic Moore sentence, of the form ' $\mathrm{p}$ and I do not know that p', is an absurd judgement. But these conjuncts can be taken to express only agnostic categorical belief. This leaves open whether agnostic non-categorical belief is always irrational, and this is arguably the belief state we have had in mind all along, and at any rate deserves our attention.

\section{(b) Would the Absurdity of Judging the Conjunction Show What is Wrong with Agnostic Belief?}

There is another, more general point to make here, independent of the details of Moore's paradox. Recall that the second step was to infer, 
from the apparent absurdity of judging the relevant conjunction, that there is something wrong with having the attitudes that the conjunction describes. This is a dubious inference, regardless of whether the judgement describing agnostic belief is absurd. My objection to this second step is more decisive than my objection to the first, because the objection to the first step involved consideration of some specific conjunctions and our intuitions about them. The specifics are debatable, intuitions can be pumped in different directions, and in any case perhaps new, clever conjunctions that the agnostic believer is committed to can be found. For example, consider some conjunctions that more directly describe the agnostic believer's situation:

I believe $\mathrm{h}$ and I lack evidence for it

Probably h, and there is no reason to think that $h$.

Perhaps to some people these sound odd. What follows from this about non-categorical agnostic belief? Not much, I will now argue, because such simple conjunctions do not specify enough about the agnostic believer's state.

Consider an analogy. I judge: 'I could not have done otherwise, but it was up to me whether to raise my hand'. This judgement seems very odd, and even inconsistent. How could it have been up to me if I could not have done otherwise? If we leave it at that, we suspect that the statement expresses an irrational couple of beliefs. However, suppose that we do not leave it at that and further specify that I am a compatibilist philosopher. I believe a whole, further theory that also addresses opposing intuitions about the relevant concepts and explains why the conjunction sounds odd. Without filling in the relevant compatibilist theory of what 'up to me' means, we would not expect someone to hear the conjunction as something normal, or even coherent. In fact, that is what the philosophical theory of compatibilism is supposed to do: make sense of apparently conflicting claims. Furthermore, the compatibilist thinks that rejecting the possibility that the two conjuncts are compatible leads one into deeper philosophical trouble, and perhaps it leads one into endorsing an even more absurd-sounding conjunction.

So, we should not take the fact that the isolated conjunction sounds odd, in conversation or in thought, as a good indication of whether compatibilism is a rational theory to hold. In general: when evaluating a position, we should not just pick two sentences from it and conjoin them to see how it sounds. We should consider the entire 
position or theory, especially when the rest of the theory contains an explanation of why the two conjuncts may sound odd together even though they are both true.

Plausibly, this fits the case of the agnostic believer, or the view that agnostic belief is not always irrational. Agnostic belief may, and perhaps should, be accompanied by the claim that no attitude about $p$ whatsoever is non-arbitrarily justified, since evidence does not bear on the issue at all, or it is outside the scope of epistemic standards. So, rather than consider just the conjunction, ' $\mathrm{I}$ believe $\mathrm{h}$ and there is no evidence for h', we should consider:

I believe $h$ and evidence is silent on $h$, so I have no reason to have any attitude whatsoever about it; $h$ is the sort of proposition that is outside the scope of non-arbitrary epistemic reasons; from the perspective of accuracy, no attitude is more justified than any other about $\mathrm{h}$, but nor is any attitude forbidden...

Consider also that our practice of evaluating beliefs, and particularly evaluating them for support by evidence and overall coherence, usually takes place in everyday contexts in which evidence is at play and on the table. That is, evidence bears on the vast majority of beliefs that we usually evaluate. But agnostic belief is, explicitly, different. So, we should expect that our kneejerk reactions to the mere fact that one is agnostic and also believes are not as accurate as our careful consideration of the entire situation. In other words, we should reflect, reason, and do philosophy in order to figure out what is wrong, if anything, with agnostic belief when it is accompanied by an epistemological theory.

\section{CONCLUSION: WITH RESERVATIONS \\ AND CONCESSIONS, AGNOSTIC BELIEF NEED NOT BE IRRATIONAL}

The question I set out to answer is: What is wrong with agnostic belief, from the epistemic perspective of accuracy? I considered what I take to be the three main ways to answer it by showing that it is always irrational to be an agnostic believer. But none of those answers succeeded, so I do not think they can explain what is wrong with agnostic belief. It seems, then, that agnostic belief might be defensible after all. This does not imply, of course, that all agnostic beliefs are 
defensible. My aim in this section is to consider what features a defensible agnostic belief must have. To do this, I discuss the concessions made above in defending agnostic belief from the various challenges posed by the three attempted answers, as well as some additional issues that arise about agnostic belief.

\section{(a) On the Partial, or Non-categorical Nature of the Agnostic's Belief}

In order to defend agnostic belief against the various arguments considered above, I have suggested that it cannot involve a categorical belief. The content, $\mathrm{h}$, cannot be used in an unqualified way in one's reasoning or plainly asserted in communication in all contexts. It is, in other words, not anything like a certainty for the believer. Instead, agnostic belief in h should be a state of confidence in $h$, where one 'thinks' that $h$, or perhaps one is pretty sure, but not certain, that $h$. The agnostic believer expects, to some degree, that $\mathrm{h}$ is true, but not unreservedly or unqualifiedly.

What, then, can the agnostic believer assert, to herself in thinking or others in communication, if not the content of her belief, h? As a believer, the agnostic believer does not hold merely that it might be that $h$ is true; she should be willing to assert more than just 'maybe $h$ '. A more confident agnostic believer could assert 'I think that h', 'I am pretty sure that h', or even 'probably h'. But a more conservative agnostic believer should stick with more reserved expressions such as 'it may well be that h'. In all of these cases, the possibility of h has not been foreclosed and is thought to be more plausible than not-h.

Another noteworthy aspect of agnostic belief's non-categorical nature is that it may still feel categorical, or practically certain, to the subject. Agnostic belief may feel like a practical certainty because inquiry into $h$ is closed, and this is a central characteristic of categorical belief as Owens and Huemer characterize it. But in the case of $h$, inquiry and evidence are off the table by default, because there can be no such evidence according to her agnosticism. In other words, the case is closed because of the content of the belief (or the nature of the hypothesis), not because of the attitude that the subject has towards the content. So while it may feel like some sort of practical certainty, defensible agnostic belief in $\mathrm{h}$ is not categorical belief, since it is held in conjunction with recognition that $\mathrm{h}$ may be false. 
That agnostic belief involves the closure of investigation, and thus feels like categorical belief, distinguishes it from some other states that one may have associated with agnosticism. For instance, Friedman ${ }^{35}$ has recently offered both a compelling case against reducing agnosticism to a degree of confidence-which is completely independent of any of the considerations I have offered-and a positive suggestion about what attitude agnosticism consists in. Her positive suggestion is that being agnostic is, roughly, keeping an inquiry open. To be agnostic is to consider it unsettled whether $h$, and therefore to continue to inquire about it. However, I doubt that openness, or inquiry, are necessary ingredients in agnosticism. I have described a type of agnosticism in which the agnostic takes there to be no foreseeable way to get evidence about $\mathrm{h}$, so further inquiry would be futile. Inquiry, at least in the sense of consulting one's sources of evidence, into $\mathrm{h}$ is closed for my agnostic. So even if we take continuing an inquiry about something to be an available doxastic state in general, this state does not seem to be justified by, let alone an essential part of, agnosticism.

Perhaps other facts about one's situation, over and above the facts that justify second-order agnosticism, make it reasonable to open some other sort of inquiry. For example, if you think that no known sources of evidence are available only because our concepts are underdeveloped here, then you may attempt a conceptual shift. That is a sort of inquiry. But notice two things: first, this is not essential to the sort of agnosticism I described, rather it is something that could happen in some such cases. Second, this is not a straightforward search for evidence. It is, in effect, a search for new kinds of evidence, or a new kind of question to investigate (since the concepts expressed in the question are being changed).

\section{(b) What Else Should the Agnostic Believer Believe and Do?}

The agnostic believer should hold some further attitudes about the status of her beliefs, aside from merely that the belief is not justified by evidence. The agnostic believer should think that epistemic norms, or 
rationality, have nothing non-arbitrary to say about whether to believe $h$. If instead one regards the lack of evidence for $h$ as a good, significant reason to withhold belief in $\mathrm{h}$ (say, because one is not one of James' adventurous types), then it would indeed seem incoherent, or inconsistent, for one to go on and believe $h$ anyway. The agnostic believer need not regard her belief in $\mathrm{h}$ as positively justified, but she should certainly not regard her own belief in $\mathrm{h}$ as forbidden, or a bad thing to believe from an epistemic perspective. In other words, the agnostic believer must regard the significance of her lack of evidence for $h$ as no indication at all about what to think about $h$.

As I noted above, non-categorical belief presumably explains and causes actions. Is there anything distinctive about the way agnostic belief explains and causes actions, or should? Given that the agnostic believer holds that evidence does not support her belief, it seems right for her to exercise caution and humility when acting on her belief, especially when the action affects others' well-being. And, when expressing her belief in $\mathrm{h}$, it seems she should specify (if the context is appropriate) that the evidence does not support it.

How can an agnostic believer take her belief seriously as a premise in her own thinking, given that she aims at accuracy and she knows that there is no indication that $\mathrm{h}$ is true? This has been addressed above to some extent, when I suggested that she should not use the premise that $h$ in her reasoning (or in thinking to herself) without qualification in every context. Her thinking to herself that $h$, when she is in the process of reasoning to some other, descriptive or factual conclusion, should be framed, either explicitly or in the way it is used in the context, under the proviso that she has no reliable indication that $\mathrm{h}$ is true. This should insulate her from concluding anything much about the world on the basis of $h$, with any confidence, solely on the basis of h. In other words, her confidence that $h$ is true is entirely epistemologically detached from her other beliefs about the world, cut off from her inferences about the here and now. This is not an overly restrictive constraint, because, by hypothesis, the content of her belief, h, has no relevant informational connection to things about which we can get evidence, or else it is not a candidate for secondorder agnosticism (see section I). So it is not clear how an inference could take one from $h$ to conclusions that can ever be verified anyway. This leaves open, however, that the agnostic believer's confidence in $h$ stimulates non-doxastic states such as wondering about $h$, and perhaps some affective attitudes arising from whatever the details of $h$ 
are. Perhaps some things are reasonable to hope for only given $h$, so those hopes are enabled by agnostic belief.

If two agnostics disagree about whether $h$ is true-that is, one of them is an agnostic believer and the other is an agnostic non-believer-what is the upshot of the disagreement? What do they learn from each other in their disagreement? It seems that neither of them learns about the probability of $h$, since both think that evidence for $h$ is absent. Rather, each one learns something about the other's doxastic policies or inclinations. The non-believer, for example, learns that the believer is an adventurous type when it comes to such topics, and this may be valuable information about a member of one's epistemic community. It seems important, then, for the agnostic believer to present her belief as it is, unsupported by evidence, when engaging in debate.

As for basing decisions that primarily affect one's own life, it seems the consequences of agnostic belief can be both intellectually and emotionally significant. How could acting on h produce some significant and noticeable effect, given how removed $h$ must be from the problems and issues encountered in this world? $\mathrm{H}$, after all, cannot be indicated or implicated in any way by anything one experiences or foresees experiencing, or else it is not a candidate for justified secondorder agnosticism (see section I). But the agnostic believer may well spend more time wondering, for example, what the transcendent realm is like, or how this affects the significance of her current life. Perhaps this results in new affective attitudes towards this life that she would otherwise lack. To see this, consider one last example.

Consider an ' $h$ ' that concerns a transcendent reality in which we somehow live on, beyond this life. That you think $\mathrm{h}$ might well be the case would explain your wondering about what this further life might be like, what the relation between your current life and this further realm is, and so on. Schellenberg ${ }^{36}$ has even suggested that certain forms of ritual are made rational by such 'wondering' or imaginative attitudes befitting an agnostic or 'sceptic' (whether or not the agnostic believes). It seems to me that these activities are not philosophically trivial. Even if such reflections and attitudes turn out to be a-rational, or outside the scope of the sorts of reasons and evidence that this life 
provides, they are the sort of reflection that an agnostic believer can engage in without any incoherence or blatant irrationality.

\section{BIBLIOGRAPHY}

Avnur, Yuval. 'Mere Faith and Entitlement'. Synthese 189, no. 2 (2012a), pp. 297-315.

Avnur, Yuval. 'In Defence of Secular Belief'. In Oxford Studies in Philosophy of Religion, edited by Jonathan Kvanvid (Oxford: Oxford University Press, 2012b).

Avnur, Yuval. 'Denial, Silence, and Openness'. The Meaning and Power of Negativity, edited by Ingolf Dalferth (Tübingen: Mohr Siebeck, forthcoming).

Chignell, Andrew. 'Belief in Kant'. Philosophical Review 116, no. 3 (2007), pp. 323-60.

Chislenko, Eugene. 'Moore's Paradox and Akratic Belief'. Philosophy and Phenomenological Research 91, no. 3 (2014).

Christensen, David. Putting Logic in its Place: Formal Constraints on Rational Belief (Oxford: Oxford University Press, 2004).

Coliva, Annalisa. 'How to Commit Moore's Paradox. Journal of Philosophy 112, no. 4 (2015), pp. 169-92.

Friedman, Jane. 'Rational Agnosticism and Degrees of Belief'. Oxford Studies in Epistemology 4 (2013), pp. 57-81.

Gendler, Tamar Szabó. 'Alief and Belief'. Journal of Philosophy, 105, no. 10 (2008), pp. 634-63.

Gleiser, Marcello. The Island of Knowledge (New York: Basic Books, 2015).

Goldman, Alvin I. (1979) 'What is Justified Belief?', Epistemology: An Anthology, edited by Ernest Sosa and Jaegwon Kim (Oxford: Blackwell, 1979), pp. 340-53.

Hawthorne, John; Rothschild, Daniel, and Levi Spectre. 'Belief is Weak'. Philosophical Studies 173, no. 5 (2016), pp. 1393-404.

Horowitz, Sophie. 'Epistemic Akrasia'. Noûs 48, no. 4 (2014), pp. 718-44.

Huemer, Michael. 'Moore's Paradox and the Norm of Belief'. In Themes From G. E. Moore: New Essays in Epistemology and Ethics, edited by Susana Nuccetelli and Gary Seay (Oxford: Clarendon Press, 2007).

Huxley, Thomas Henry. 'Agnosticism: A Symposium'. In The Agnostic Annual, edited by Charles Watts (1884), pp. 5-6.

James, William. The Will to Believe and Other Essays in Popular Philosophy (New York: Longmans, Green, and Co., 1897 [1896]).

Lackey, Jennifer. 'Norms of Assertion'. Noûs 41, no. 4 (2007), pp. 594-626. Littlejohn, Clayton. 'Moore's Paradox and Epistemic Norms'. Australasian Journal of Philosophy 88, no. 1 (2010), pp. 79-100. 
Monton, Bradley. 'Bayesian Agnosticism and Constructive Empiricism'. Analysis 58, no. 3 (1998), pp. 207-12.

Moran, Richard A. Authority and Estrangement: An Essay on Self-Knowledge (Princeton: Princeton University Press, 2001).

Owens, David. Reason without Freedom: The Problem of Epistemic Normativity (London: Routledge, 2000).

Plantinga, Alvin. Warranted Christian Belief (New York: Oxford University Press, 2000).

Ribeiro, Brian. 'Epistemic Akrasia'. International Journal for the Study of Skepticism 1, no. 1 (2011), pp. 18-25.

Rosenkranz, Sven. 'Agnosticism as a Third Stance'. Mind 116, no. 461 (2007), pp. 55-104.

Russell, Bertrand. 'Is There a God?'. The Collected Papers of Bertrand Russell, Vol. 11: Last Philosophical Testament, 1943-68 (London: Routledge, 1952), pp. 547-8.

Schellenberg, J.L. Prolegomena to a Philosophy of Religion (Ithaca, NY: Cornell University Press, 2005).

Schellenberg, J.L. The Will to Imagine: A Justification of Skeptical Religion (Ithaca, NY: Cornell University Press, 2009).

Schellenberg, J.L. Evolutionary Religion (Oxford: Oxford University Press, 2013).

Schellenberg, J.L. The Hiddenness Argument: Philosophy's New Challenge to Belief in God (Oxford: Oxford University Press, 2015).

Schellenberg, J.L. 'Three Ways to Improve Religious Epistemology'. Philosophy (forthcoming).

Sober, Elliott. 'Absence of Evidence and Evidence of Absence: Evidential Transitivity in Connection with Fossils, Fishing, Fine-tuning, and Firing squads'. Philosophical Studies 143, no. 1 (2009a), pp. 63-90.

Sober, Elliott. 'Parsimony Arguments in Science and Philosophy-A Test Case for Naturalism'. Proceedings and Addresses of the American Philosophical Association 83, no. 2 (2009b), pp. 117-55.

Unger, Peter K. Philosophical Relativity (Oxford: Oxford University Press, 1984).

Van Leeuwen, Neil. 'Religious Credence is not Factual Belief'. Cognition 133, no. 3 (2014), pp. 698-715.

White, Roger. 'Problems for Dogmatism'. Philosophical Studies 131, no. 3 (2006), pp. 525-57.

Williamson, Timothy. Knowledge and its Limits (Oxford: Oxford University Press, 2000).

Wright, Crispin. 'Warrant for Nothing?' Aristotelian Society Supplementary Volume 78, no. 1 (2004), pp. 167-212. 